\title{
Aortic valve replacement for severe aortic regurgitation caused by idiopathic giant cell aortitis
}

\author{
AJAIB S SOORAE, FLORENCE McKEOWN, AND JACK CLELAND \\ From the Cardiac Surgical Unit and Department of Pathology, Queen's University, \\ Royal Victoria Hospital, Belfast, Northern Ireland
}

ABSTRACT Giant cell aortitis occurred in a 25-year-old woman, with absent pulses in the left armo and severe aortic regurgitation from dilatation of the valvar annulus. The aortic valve was replaced by a Starr-Edwards prosthesis, and the patient was treated with steroids. Five years later, she continues asymptomatic and haemodynamically stable. The left brachial and radialo pulses have returned.

Giant cell aortitis can be a cause of aortic regurgitation, but it is rarely of such severity as to warrant valve replacement. A review of published reports showed only four such cases. ${ }^{1-3}$ Two of these patients also had aneurysmal dilatation of the ascending aorta. ${ }^{12} \mathrm{We}$ report a case of giant cell aortitis in a 25-year-old woman who had absent pulses in the left arm and severe aortic regurgitation from dilatation of the valve ring. The patient was successfully treated by aortic valve replacement and steroids.

\section{Case report}

A 25-year-old woman was admitted to hospital in January 1974 with a two-year history of increasing tightness in the chest, dyspnoea on exertion or excitement, and frequent temporal headaches. She gave no history of rheumatic fever, chorea, arthritis, tuberculosis, venereal disease, or polymyositis, and there was no family history of heart disease. Her right eye had been enucleated for retinoblastoma at the age of 2 years. Three years before her present admission she had an ovarian cystectomy that was followed by pulmonary embolism, necessitating anticoagulation. Six months later, on a routine medical examination, she was found to have a precordial aortic diastolic murmur.

She was pale and had absent left brachial and radial pulses and feeble pulses in the right arm. The pulse was regular. The blood pressure in the

Address for reprint requests: Jack Cleland, FRCS, Cardiac Surgical Unit, Royal Victoria Hospital, Grosvenor Road, Belfast BT12 6BA, Northern Ireland. right arm was $100 / 65 \mathrm{mmHg}$, and $260 / 60 \mathrm{mmHg}$ in the legs. It was unrecordable in the left arm. The jugular venous pressure was normal, buto there was prominent carotid pulsation. The apex beat was diffuse and heaving, with a diastolic thrillo over the left parasternal border. Both heart soundső were audible with a harsh, ejection systolic mur-卫 mur, grade $3 / 6$ in the aortic area, loudest over $\overrightarrow{0}$ both the carotid arteries and a grade $3 / 6$ early 3 diastolic murmur along the left parasternal border. There was no hepatomegaly, ascites, or oedema.

A chest radiograph showed moderate cardiomegaly with pulmonary venous congestion in the upper lobes. The electrocardiogram showed sinus? rhythm, and left ventricular hypertrophy. The haemoglobin was $10.7 \mathrm{~g} / \mathrm{dl}$, the haematocrit $33 \%$ and the erythrocytes normochromic and normocytic. The white cell count was $5.4 \times 10^{9} / 1$ and the ESR was $58 \mathrm{~mm}$ in one hour (Westergren). Blood urea, serum electrolytes, and liver function tests were all normal. C-reactive protein was positive Antistreptolysin titre, antinuclear factor, and serology for rheumatoid factor were all negatives No LE cells were seen. Cardiac catheterisation data (right and left) are shown in the table, con firming severe left ventricular dysfunction. Aor? tography showed gross aortic regurgitation, greatlyo increased left ventricular volume, and poor con tractions (ejection fraction $45 \%$ ). No mitral re? gurgitation was seen.

At operation, under standard cardiopulmonar, bypass with coronary perfusion, the ascending aorta was found to be oedematous and grossl thickened (fig 1), which gave rise to considerable difficulty with aortic cannulation. The intima 
Table Cardiac catheterisation data (mean pressure in parentheses)

\begin{tabular}{lll}
\hline Cardiac chamber & Pressure $(\mathrm{mmHg})$ & \\
\hline Right atrium & $\mathrm{x}-4, \mathrm{v} 4, \mathrm{y} 2$ & $(1)$ \\
Right ventricle & $36 / 4$ & \\
Pulmonary artery & $38 / 18$ & $(25)$ \\
Pulmonary artery wedge & $\mathrm{a} 20, \mathrm{x} \mathrm{16,} \mathrm{v} \mathrm{22,} \mathrm{y} 12$ & $(18)$ \\
Aorta & $140 / 40$ & $(65)$ \\
Left ventricle & $140 / 15$ a 30 & \\
Cardiac index $\left(1 / \mathrm{min} / \mathrm{m}^{2}\right)$ & $2 \cdot 8$ & \\
Left ventricle ejection fraction & $45 \%$ & \\
\hline
\end{tabular}

looked scarred, and was covered with pale opaque areas. The aortic cusps showed some shortening, but the basic lesion was dilatation of the valve ring causing aortic incompetence. The valve was excised and replaced by a cloth-covered, No 2320 , size 11-A Starr-Edwards prosthesis, and a biopsy specimen of the aortic wall was taken.

Histologically there was a severe inflammatory infiltration that affected the outer half of the media and the adventitia (fig 2). The inflammatory cells were mainly lymphocytes, with a few histiocytes and plasma cells. Scattered multinucleated giant cells were noted in the media (fig 3). There was much adventitial fibrosis and endarteritis of occasional vasa vasorum. The picture was that of a florid giant cell aortitis associated with extensive medial destruction. The aortic cusps were thin and normal in structure on histological examination.

Recovery was complicated by atrial fibrillation that spontaneously reverted to sinus rhythm. The patient was given prednisone $15 \mathrm{mg}$ thrice daily in addition to anticoagulants and digoxin. After

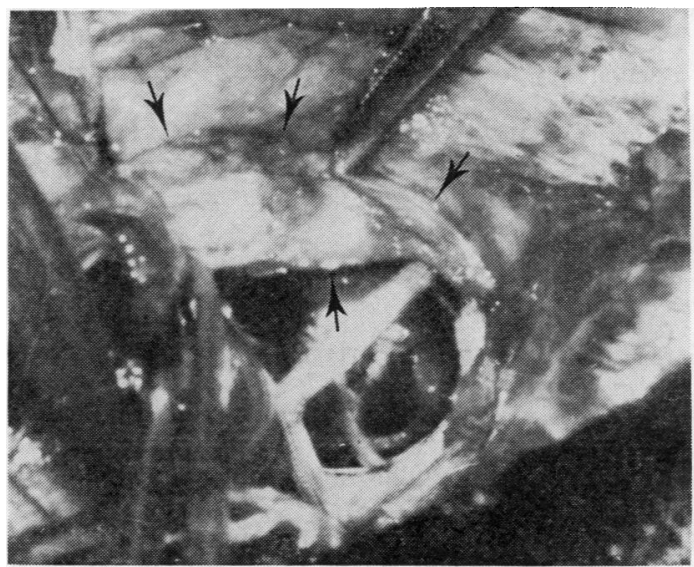

Fig 1 Grossly thickened and oedematous ascending aorta (arrows). six months the left brachial and radial pulses were palpable, the ESR had returned to normal, and the $\mathrm{C}$-reactive protein was consistently negative. On her last follow-up, five years after operation, she was asymptomatic and haemodynamically stable with a blood pressure of $130 / 90$ $\mathrm{mmHg}$ in both arms. The heart had returned to normal size, but the ECG still showed evidence of slight left ventricular hypertrophy. At present she takes a small maintenance dose of prednisone.

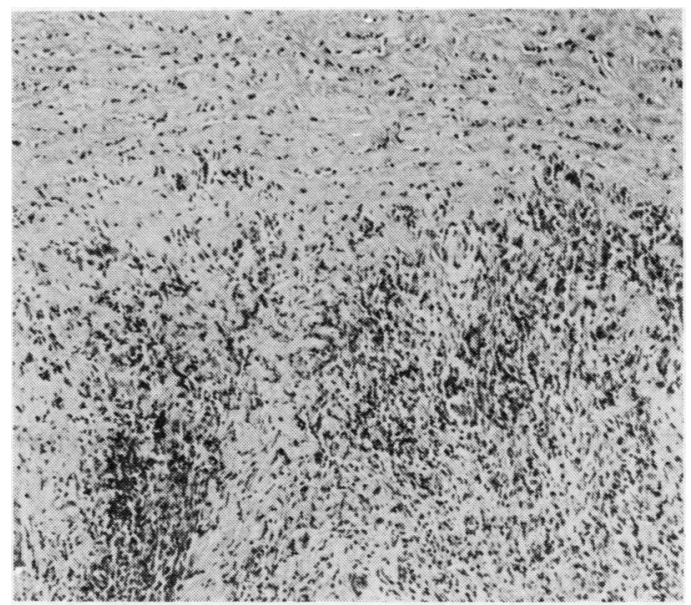

Fig 2 Aortic wall, showing heavy inflammatory infiltration in outer media and adventitia.

Haematoxylin and eosin, original magnification $\times 80$.

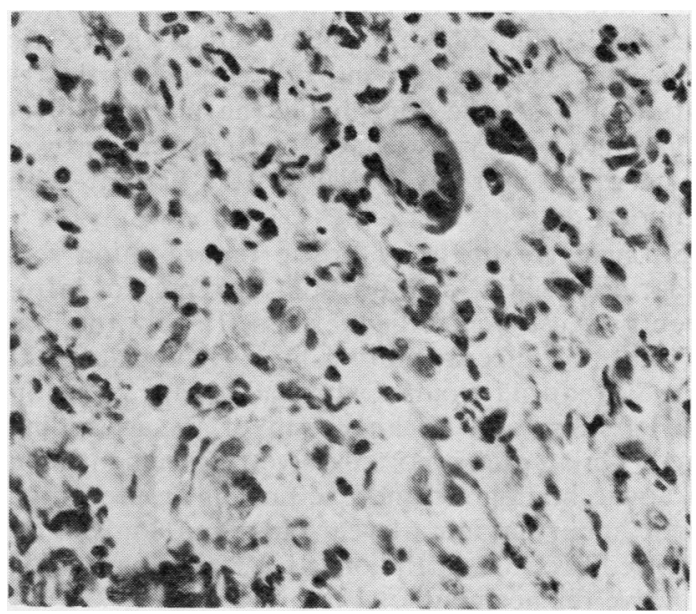

Fig 3 Giant cells admixed with lymphocytes and histiocytes in aortic media. $H$ \& E, original magnification $\times 250$. 


\section{Discussion}

The aetiology of giant cell aortitis is unknown. The panarteritis that occurs may be indistinguishable from that recorded in Takayasu's disease, and the differential diagnosis is based almost entirely on the distinctive age incidence. Nevertheless, Takayasu's disease, the onset of which is usually between the ages of 10 and 20 years, has occasionally been diagnosed in the elderly, and giant cell arteritis is not exclusively a disease of the older age groups. There is the same female preponderance in the aortic arch syndrome from giant cell arteritis as in classical Takayasu's disease. ${ }^{4}$ The suggestion by Cairns and Oleesky ${ }^{5}$ that the two diseases represent a single entity and form components of a continuous spectrum of inflammatory arterial disease has much to recommend it. The proposal by Hall, ${ }^{6}$ that the term "idiopathic arteritis" should be applied to cranial arteritis, polymyalgia rheumatica, and Takayasu's disease, since they possibly represent different manifestations of one underlying disorder, is rational.

Current opinion favours an autoimmune aetiology. Antiarterial antibodies have been shown in some cases, ${ }^{78}$ but whether they are primarily implicated in the arterial damage is uncertain.

The aortic medial inflammation and necrosis that characterise the disease may extend into or cause obstruction of the major vessels arising from the arch of the aorta, resulting in inequality or absence of the pulses, as observed in this case. Stenosis or dilatation of the aortic lumen may occur with aneurysm formation ${ }^{910}$ and dissection may develop, especially in the presence of hypertension. ${ }^{11}$ The dilatation may affect the aortic valve ring causing varying degrees of aortic regurgitation. On the other hand, the aortic involvement may be asymptomatic, as has been proved at necropsy in some patients who present with temporal arteritis.

Surgical treatment of aortic regurgitation secondary to giant cell aortitis is reported infrequently. Austen and Blennerhassett ${ }^{1}$ were the first to treat aortic regurgitation by valve replacement in a 30-year-old woman who had absent pulses in the left arm and an aneurysm of the ascending aorta. Gula et $a l^{2}$ reported valve replacement with an aortic homograft and excision of an ascending aortic aneurysm in a 61-year-old man. Honig et $\mathrm{al}^{3}$ reported two cases with aortic regurgitation treated by valve replacement.

The course of giant cell arteritis varies in different patients. In some it becomes arrested with or without treatment, whereas in others it leads to death. Steroids have been effective in some patients, and in the present case there was of dramatic improvement after a course of pred $\overline{\bar{p}}$ nisone, the brachial and radial pulses returning and the ESR becoming normal, suggesting an arrest of the disease. The patient is asymptomaties five years after valve replacement while continuing $\vec{D}$ to take a small dose of prednisone. This is the longest reported follow-up after operation. Treat ment with steroids, therefore, appears to be justi fied after aortic valve replacement in these cases None of the other patients treated surgically was given steroids after operation.

The clinical diagnosis of giant cell aortitis as $\stackrel{P}{P}$ cause of rapidly progressive aortic regurgitation is extremely difficult. Nevertheless, it should besuspected in a relatively young patient with now history of rheumatic fever but with polymyalgia? headaches, pyrexia, malaise, or weight loss. IN addition some patients may have absent or dimin ished pulses, considerably raised ESR, and normo chromic, normocytic anaemia. Final confirmation can only be achieved by biopsy.

We thank Dr D Boyle who referred this patiento for operation.

\section{References}

1 Austen WG, Blennerhassett JB. Giant cell aortitis? causing an aneurysm of the ascending aorta and aortic regurgitation. Engl J Med 1965; 272:80-3. 으

2 Gula G, Pomerance A, Bennet M, Yacoub MH Homograft replacement of aortic valve and ascending aorta in a patient with non-specifie giant cell aortitis. Br Heart J 1977; 39:581-5.

3 Honig HS, Weintraub AM, Gomes MN, Hufnage CA, Roberts WC. Severe aortic regurgitation secondary to idiopathic aortitis. Am J Med 1977? 63:623-33.

4 Swinson DR, Goodwill CJ, Talbot IC. Giant celㄹ. arteritis presenting as subclavian artery occlusionN a report of two cases. Postgrad Med J 1976; 52? $525-9$.

5 Cairns SA, Oleesky S. Takayasu's disease and giant cell arteritis-a single disease? Br Med fo 1977; 2:127.

6 Hall GH. Giant cell arteritis-an unholy trinity Am Heart J 1973; 85:835-7.

7 Nakao K, Ikeda M, Kimata S-I, et al. Takayasu's arteritis. Clinical report of eighty-four cases and immunological studies of seven cases. Circulation 1967; 35:1141-55.

8 Hazleman BL, MacLennan ICM, Esiri MM Lymphocyte proliferation to artery antigen as positive diagnostic test in polymyalgia rheumatica. Ann Rheum Dis 1975; 34:122-7. 
9 Kent DC, Arnold H. Aneurysm of the aorta due to giant cell aortitis: successful surgical correction. J Thorac Cardiovasc Surg 1967; 53:572-7.

10 Zumbro GL, Henley LB, Treasure RL. Saccular aneurysm of ascending aorta caused by granu- lomatous aortitis in a child. $J$ Thorac Cardiovasc Surg 1975; 69:397-401.

11 Harris M. Dissecting aneurysm of the aorta due to giant cell arteritis. Br Heart $J$ 1968; 30: $840-4$. 